\title{
Post-Surgical Quality of Life, Psychological State and what Patients Think about the Effectiveness of Heller Myotomy in the Treatment of Achalasia
}

\author{
Qualidade de Vida Pós-Cirúrgica, Estado Psicológico e \\ Perspetiva dos Doentes Relativamente à Miotomia de Heller \\ no Tratamento da Acalásia
}

\author{
Telma VALE-FONSECA $\triangle^{1,2}$, Luís FERREIRA-PINTO ${ }^{3,4,5}$, Margarida FIGUEIREDO-BRAGA ${ }^{6}$, Silvestre CARNEIRO ${ }^{1,2}$ \\ Acta Med Port 2016 Feb;29(2):107-113 - http://dx.doi.org/10.20344/amp.6758
}

\section{ABSTRACT}

Introduction: The disruption of esophageal motility that characterizes achalasia typically provokes dysphagia, pain, loss of weight and malnutrition. Therefore, patients frequently report a reduction in quality of life and negative emotional states. Laparoscopic Heller myotomy proved to be an effective therapy, enabling the resumption of good quality of life.

Material and Methods: The authors studied 45 patients previously submitted to laparoscopic Heller myotomy. Postoperative evaluation was performed using a customized version of the achalasia disease-specific quality of life questionnaire. Quality of life and the presence of depressive and anxiety symptoms were assessed using the Portuguese versions of the Medical Outcomes Study SF-36 and the Hospital Anxiety and Depression Scale.

Results: Thirty-one patients responded to the survey. Dysphagia was the main clinical symptom before surgery. A clear improvement in dysphagia, regurgitation, pain and weight loss was found after surgery $(p<0.001)$. The Mental Health domain of SF-36 presented a Pearson correlation coefficient of -0.689 with HADS-D and of -0.557 with HADS-A $(p<0.001$ and $p=0.002$, respectively).

Conclusion: This study demonstrates that the Heller myotomy is associated with a good quality of life in patients with achalasia and strengthens the evidence that this is a safe and reliable procedure.

Keywords: Anxiety; Depression; Digestive System Surgical Procedures; Esophageal Achalasia; Laparoscopy; Quality of life.

\section{RESUMO}

Introdução: A interrupção da motilidade esofágica que caracteriza a acalásia provoca disfagia, dor, perda de peso e desnutrição. Portanto, estes doentes referem uma redução na qualidade de vida e apresentam estados emocionais negativos. Procedimentos cirúrgicos, como a miotomia de Heller, têm-se revelado eficazes, permitindo retornar a uma qualidade de vida melhor.

Material e Métodos: Foram incluídos no presente estudo 45 pacientes submetidos a miotomia de Heller. A avaliação pós-operatória foi realizada usando uma versão modificada do questionário de Qualidade de Vida Específico para a Acalasia. A qualidade de vida e a presença de sintomas psicológicos foram avaliados utilizando a versão portuguesa do Medical Outcomes Study SF-36 e a Escala de Ansiedade e Depressão Hospitalar.

Resultados: Um total de 31 doentes (69\%) foi avaliado, média de idades de 53 anos (18). A disfagia foi o principal sintoma clínico. Uma clara melhoria da disfagia, regurgitação, dor e perda de peso foi evidenciada após a cirurgia $(p<0,001)$. O domínio da saúde mental do SF-36 apresentou um coeficiente de correlação de Pearson de -0,689 com HADS -D e de -0,557 com HADS-A ( $p<0,001$ e $p=0,002$, respetivamente).

Conclusão: Este estudo demonstra que a miotomia de Heller se associa a uma boa qualidade de vida nos doentes com acalásia e reforça a ideia de que este é um procedimento seguro e eficaz.

Palavras-chave: Acalasia Esofágica; Ansiedade; Depressão; Laparoscopia; Procedimentos Cirúrgicos do Sistema Digestivo; Qualidade de vida.

\section{INTRODUCTION}

Achalasia is a rare esophageal motility disorder ${ }^{1,2}$ characterized by the disruption of the normal functioning of the esophageal peristaltic wave and of the lower esophageal sphincter ${ }^{3}$ due to degenerative changes of the myenteric plexus. ${ }^{1,3}$ This condition may occur at any age, with an increased incidence between the third and fifth decade, and shows no gender predilection. ${ }^{4}$ Typical symptoms are dysphagia for both solid and liquid food, chest pain,

regurgitation ${ }^{1,3}$ and in more advanced stages, loss of weight and malnutrition. ${ }^{1}$

Currently, the treatment is based on palliative options that reduce the pressure of lower esophageal sphincter $(\text { LES })^{5}$ and relieves the main symptoms of achalasia. ${ }^{6}$ Endoscopic botulinum toxin injection and endoscopic balloon dilation have been successfully used, but patients who were submitted to multiple endoscopic treatments

\footnotetext{
1. Faculty of Medicine. University of Porto. Porto. Portugal.

2. Department of General Surgery. Hospital of São João. Porto. Portugal.

3. Department of Orthopedic Surgery. Centro Hospitalar Tondela-Viseu. Viseu. Portugal.

4. Center for Health Technology and Services Research - CINTESIS. Porto. Portugal.

5. Department of Health and Decision Sciences - CIDES. Faculty of Medicine. University of Porto. Porto. Portugal.

6. Department of Clinical Neurosciences and Mental Health. Faculty of Medicine. University of Porto. Porto. Portugal.

$\triangle$ Autor correspondente: Telma Vale-Fonseca. tnvfonseca@gmail.com

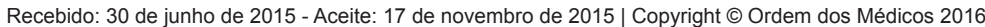


prior to Heller myotomy are associated with poorer surgical outcomes. ${ }^{7}$ Thus, the gold standard procedure is minimally invasive and Heller myotomy with partial fundoplication ${ }^{1,8}$ is probably the most widespread and most effective surgical technique. ${ }^{9}$ Some series of laparoscopic myotomies reported improvement of symptoms in $85 \%$ to $100 \%$ of patients, with very low rates of morbidity and mortality 8,10 and consistent long-term satisfaction (higher than 90\%). ${ }^{8} \mathrm{New}$ and less invasive approaches, such as perioral esophageal myotomy and robot-assisted surgeries, must be considered as more precise and safer surgical procedures rather than laparoscopic myotomy with enhanced beneficial effect in post-surgical quality of life. ${ }^{11}$

Patients with achalasia present an insidious and progressive deterioration of their daily routine and commonly experience loss of physical strength, fatigue, frustration and even strain in personal relationships. ${ }^{6,12}$ Ekberg et al showed that $41 \%$ of patients with dysphagia presented anxiety or panic disorders during mealtime and up to one third avoid having meals in social context. ${ }^{13}$

Quality of life (QoL) is gaining increasingly importance among clinical investigators, being held as one of the main targets when evaluating the different therapeutic approaches available. ${ }^{6,14}$ Several studies have already shown that different aspects of health-related quality of life in patients with achalasia significantly improve after laparoscopic Heller myotomy and fundoplication. ${ }^{6,12,14}$ However, short-term relief or unrelieved symptoms of achalasia may suggest that the surgical procedure was not entirely successful. ${ }^{15}$ Persistence of symptoms is associated with a negative impact in social and psychological aspects, influencing negatively quality of life.., 13

This study aims to assess post-surgical quality of life of Portuguese patients with achalasia after Heller myotomy. The novelty of our study was to include the screening for anxious and depressive symptoms in the post-surgical analyses of this population, as well as to evaluate the perceived impact of this surgical procedure in patient's longterm quality of life.

\section{MATERIAL AND METHODS Patients}

The study follows a transversal observational approach and was approved by the Ethical Committee 'Comissão de Ética para a Saúde do Centro Hospitalar São João'. The confidentiality and privacy of the data were guaranteed according to the Declaration of Helsinki.

We included all patients diagnosed with achalasia and submitted to Heller myotomy in Centro Hospitalar São João, between $1^{\text {st }}$ January 2002 and $31^{\text {st }}$ December 2012, with at least an esophageal manometry, upper gastrointestinal endoscopy and barium study to confirm the diagnosis of achalasia: a total of 56 patients were eligible. Exclusion criteria included under 18 years of age, insufficient clinical data, severe comorbidities, death not related to the surgical procedure and impossibility of contact. A total of 45 patients joined the study.
Those patients were contacted by phone to establish their willingness to participate in the study. All selected patients agreed to participate. After this first contact, full information about the study, an informed consent form and the psychometric questionnaires were mailed to all participants. A $69 \%$ response rate was obtained (31 out of the 45 questionnaires sent).

All patients were submitted to a standardized surgical procedure-laparoscopic Heller myotomy and fundoplication - performed by a group of experienced surgeons. Using a laparoscopic approach, the abdominal and lower thoracic esophagus were isolated and the gastroesophageal (GE) junction was identified. The muscular layer of the gut was incised on the anterior wall of the cardia $2 \mathrm{~cm}$ distal to the GE junction, and was extended proximally for a distance of at least $8-10 \mathrm{~cm}$. The treatment was concluded by performing either a complete fundoplication or an anterior or posterior partial fundoplication.

\section{Socio and clinical characteristics}

Socio demographic characteristics - age, gender, and preoperative clinical information were obtained from the Hospital database. Patients' perceived symptoms were assessed using a questionnaire tailored to indicate the frequency and type of symptoms before surgery and at present.

To evaluate the severity of achalasia and the effectiveness of the therapeutic procedures, an adapted version of an achalasia disease-specific quality of life questionnaire (achalasia-DSQoL) developed by Urbach et $\mathrm{al}^{16}$ was used. The Portuguese version we used was translated from the original questionnaire and validated by a team of experienced surgeons of the Gastroesophageal surgery group of Centro Hospitalar São João. This questionnaire examines patients' food tolerance, dysphagia related behavior modifications, pain, heartburn, distress, lifestyle limitation and satisfaction. It is scored on a 0 100 scale, with higher values indicating higher disease severity. ${ }^{17}$ Four questions were added in order to evaluate patients'satisfaction with the surgical procedure (2 simple choice questions) as well as the symptomatology presented before and after surgery (1 grading scale symptoms list questions and 1 grading scale life impact list question).

\section{Quality of life, anxiety and depression assessment}

The Medical Outcomes Study SF-36, originally developed by the Rand Corporation in the USA ${ }^{18}$ translated and validated to the Portuguese population, ${ }^{19}$ was used to measure QoL. This questionnaire is a short, generic measure of subjective health status and evaluates eight health concepts grouped into two components: physical health (physical functioning, role limitations due to physical health, body pain and general health) and mental health (emotional problems, social functioning, general mental health and vitality). ${ }^{20}$ The scores for each health concept range from 0 to 100 , with low scores representing poorer QoL and a score of 100 representing the best QoL possible. ${ }^{18,20}$ 
Table 1 - Sample descriptive statistics $(n=31)$

\begin{tabular}{ll}
\hline $\begin{array}{l}\text { Age (years) }{ }^{a} \\
\text { Gender }{ }^{b}\end{array}$ & $53(18)$ \\
Male & $45(14)$ \\
Female & $55(17)$ \\
Age at surgery (years) ${ }^{a}$ & $47(20)$ \\
Length of hospital stay $^{c}$ & $6(2,27)$ \\
Clinical symptoms $^{b}$ & \\
Dysphagia & $92(24)$ \\
Regurgitation & $42(11)$ \\
Halitosis & $23(6)$ \\
Heartburn & $15(4)$ \\
Weight loss & $46(12)$ \\
Pain & $27(7)$ \\
Vomit & $15(4)$ \\
\hline
\end{tabular}

${ }^{a}$ mean $(\mathrm{SD}) ;{ }^{\mathrm{b}}$ percentage $(\mathrm{n}) ;{ }^{\circ}$ median (min, max).

5 patients lack information on symptoms previous to surgery

The Portuguese version of the Hospital Anxiety and Depression Scale (HADS) ${ }^{21}$ was used to assess the presence of anxiety and depressive symptoms. This questionnaire is divided into two sets of seven questions each, aiming to detect respectively, depressive and anxiety symptoms. The absence of items focused on somatic complaints improves its sensitivity in physically ill individuals. A cut-off value of 8 is accepted as indicating that a disorder is probably present.

\section{Patients' subjective perception and satisfaction with surgery}

Patients' satisfaction regarding surgery was assessed by the question 'Would you be submitted to surgery again?' and by the level of agreement with the statement
'I am satisfied with my surgical treatment of achalasia'. A five points Likert scale permitted to evaluate the degree of patients' satisfaction with surgery.

\section{Statistical Analysis}

Statistical analysis was performed using Statistical Package for the Social Sciences Software (SPSS 21.0 ${ }^{\circledR}$ ). Mean comparisons were performed using parametric (independent-samples $t$-test) and non-parametric (MannWhitney $U$ test, Wilcoxon signed rank test and KruskalWallis test) tests. Correlation was assessed through Pearson correlation coefficient. A p-value less than 0.05 was considered as statistically significant.

\section{RESULTS \\ Socio demographic, and surgical characterization}

From a population of 45 patients, 31 completed the study. Mean age of the participants was 53 years of age with a standard deviation (SD) of 18 years, $45 \%$ were males.

Before surgery, dysphagia was clearly the main clinical symptom, being experienced by more than $90 \%$ of the patients. Weight loss and regurgitation were also frequent (experienced by 46 and $42 \%$ of patients, respectively).

After the surgery there was no mortality and only minor morbidity. Median length of hospital stay was six days.

Table 1 summarizes the socio demographic and surgical characteristics of the series.

\section{Achalasia disease specific quality of life}

The mean score for achalasia disease specific quality of life (DSQoL) was 35 (SD 20). Table 2 presents the descriptive statistics concerning DSQoL. No significant differences between men and women were found in the final score of Achalasia-DSQoL.

\section{Quality of life, anxiety and depressive symptoms}

The SF-36 results had a median of 79 points in the

Table 2 - Sample descriptive statistics concerning the SF-36 Health Survey and Achalasia DSQoL

\begin{tabular}{ll}
\hline SF-36 Health Survey a & \\
\hline Physical Health & $79(35,97.5)$ \\
Mental Health & $76(41,97)$ \\
\hline Achalasia DSQoL ${ }^{\text {b }}$ & $48(15)$ \\
\hline No limitation on quality of meals & $39(12)$ \\
Mild limitation on quality of meals & $13(4)$ \\
Moderate to severe limitation on quality of meals & $29(9)$ \\
No limitation on quality of life & $71(22)$ \\
Presented limitation on quality of life & $65(20)$ \\
Satisfied with present health & $19(6)$ \\
Nor satisfied nor disappointed with present health & $16(5)$ \\
Not satisfied with present health &
\end{tabular}


physical health domain, and 76 points for the mental health omain

Anxiety and depression were experienced by $48 \%$ and $26 \%$ of patients respectively. Table 3 presents the distribution, by gender, of anxiety and depression HADS scores. Male patients presented higher values of anxiety and depression compared to female patients, but the difference was not statistically significant.

Table 4 summarizes the quality of life in men and women assessed by both Achalasia DSQoL and SF-36 Health Survey.

A Pearson correlation coefficient of -0.689 was found between the mental health domain of SF-36 and Depression score in HADS $(p<0.001)$ (Fig. 1). Independent-samples Mann-Whitney $U$ tests comparing depressive and nondepressive patients concerning each one of the four scales of mental health (role-emotional, vitality, mental health and social functioning) presented a strong decrease in all scales in depressive patients $(p<0.05)$. As for the comparison between the mental health domain of SF-36 and Anxiety score in HADS a Pearson correlation coefficient of -0.557 was found ( $p=0.002$ ) (Fig. 2). Independent-samples Kruskal-Wallis tests comparing non-anxious, mildly and moderately anxious patients concerning the four scales of mental health showed as well a clear pattern of lower results for patients with higher levels of anxiety $(p<0.05)$.

No significant differences between men and women were found in any of the scales of SF-36.

\section{Post-surgical evolution of achalasia}

When comparing clinical state before and after surgery, there was a clear improvement in dysphagia, regurgitation, pain and weight loss $(p<0.001)$ and in halitosis ( $p=0.003)$ - Wilcoxon signed rank test for paired samples. The questionnaire showed that $90 \%$ of patients are satisfied with the surgical outcome.

\section{DISCUSSION}

Many aspects of quality of life in patients with achalasia significantly improve after laparoscopic Heller myotomy

Table 3 - Distribution of HADS-A and HADS-D scores across gender

\begin{tabular}{|c|c|c|c|c|}
\hline \multirow{2}{*}{ Anxiety ${ }^{a}$} & \multirow{2}{*}{ Total } & \multicolumn{2}{|c|}{ Gender } & \multirow{2}{*}{$p$-value } \\
\hline & & Male & Female & \\
\hline Normal $(0-7)$ & $52(16)$ & $43(6)$ & $59(10)$ & \multirow{4}{*}{0.376} \\
\hline Mild $(8-10)$ & $32(10)$ & $36(5)$ & $29(5)$ & \\
\hline Moderate $(11-14)$ & $16(5)$ & $21(3)$ & $12(2)$ & \\
\hline Severe $(15-21)$ & $0(0)$ & $0(0)$ & $0(0)$ & \\
\hline \multicolumn{5}{|l|}{ Depression $^{a}$} \\
\hline Normal $(0-7)$ & $74(23)$ & $64(9)$ & $82(14)$ & \multirow{4}{*}{0.232} \\
\hline Mild $(8-10)$ & $26(8)$ & $36(5)$ & $18(3)$ & \\
\hline Moderate $(11-14)$ & $0(0)$ & $0(0)$ & $0(0)$ & \\
\hline Severe $(15-21)$ & $0(0)$ & $0(0)$ & $0(0)$ & \\
\hline
\end{tabular}

percentage $(\mathrm{n})$

$p$-values were obtained through chi-square test for anxiety and Fisher's exact test for depression; mild, moderate and severe were computed into anxious or depressive.

Table 4 - Quality of life in both men and women through SF-36 Health Survey and Achalasia DSQoL

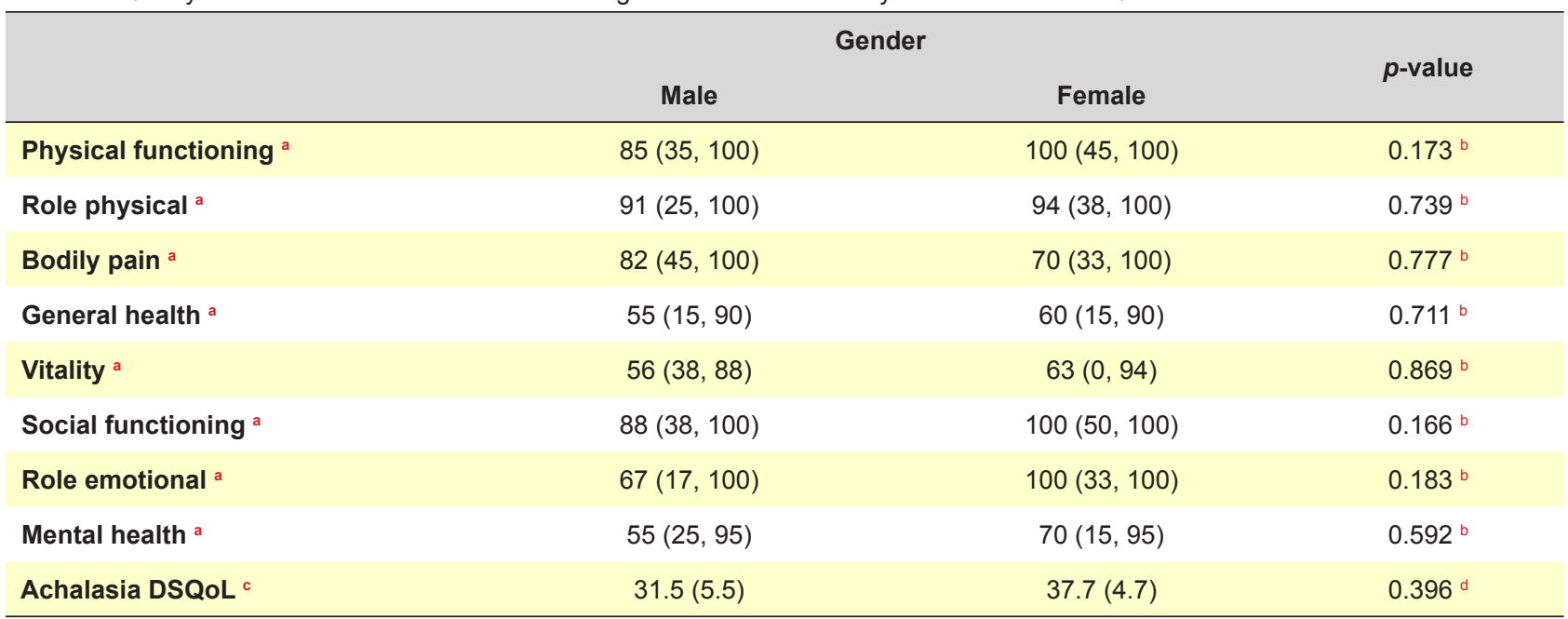

${ }^{a}$ median (minimum, maximum); ${ }^{\mathrm{b}}$ Mann-Whitney $\mathrm{U}$ test; ${ }^{\mathrm{c}}$ mean (SD); ${ }^{\mathrm{d}}$ independent-samples $t$-test. 


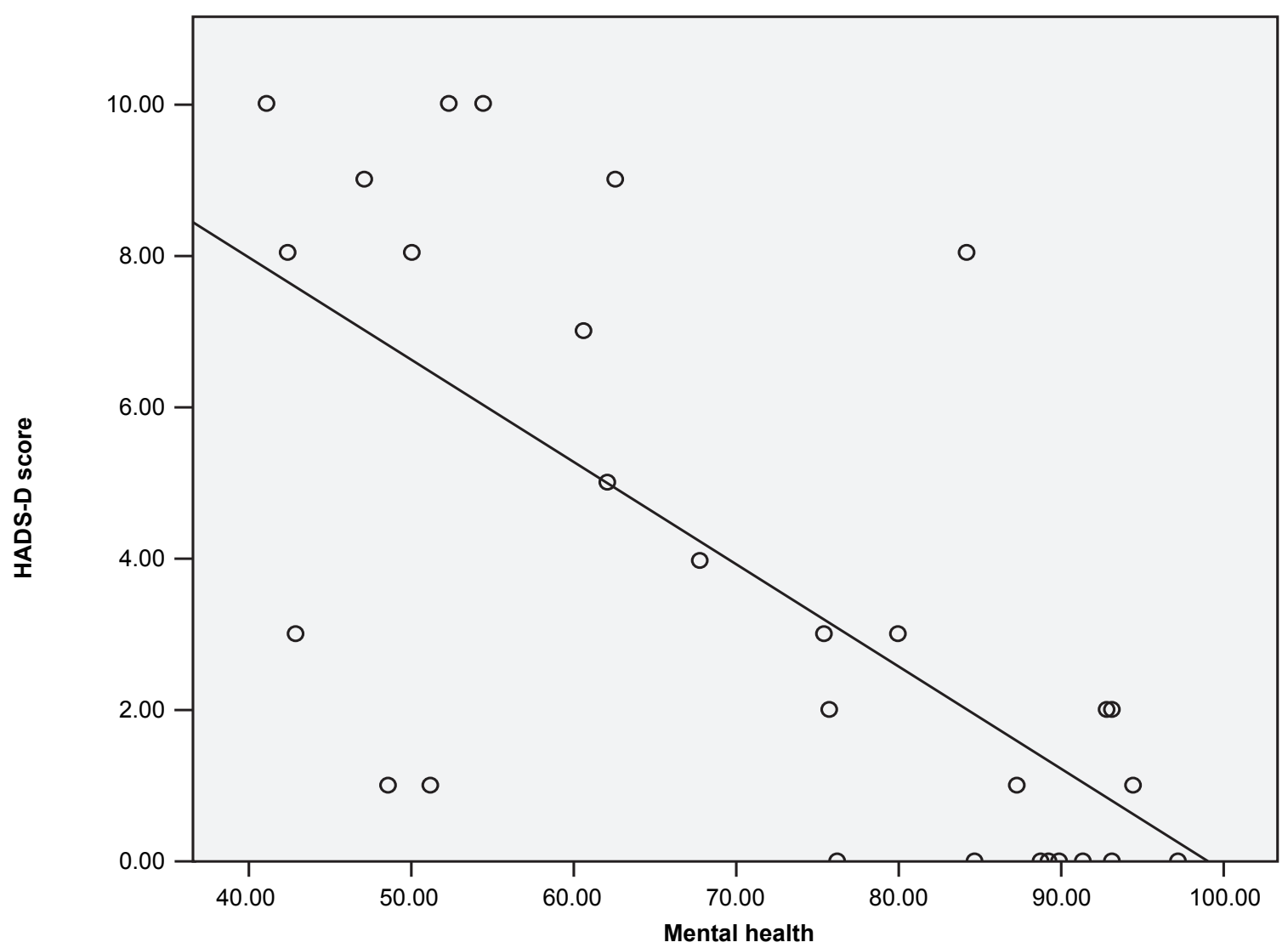

Figure 1 - Simple box plot correlating HADS-D (depression) score and the Mental Health domain of SF-36 Health Survey (Pearson correlation coefficient of -0.689 )

and fundoplication. ${ }^{6,12,14}$ However, the impact of the surgical procedure on patients' quality of life is higher on the physical component when compared to the mental one, as showed by Avid Ben-Meir et al. ${ }^{14}$ Therefore, it is important to evaluate the psychological burden of the disease, and its relationship with the patient's satisfaction with surgical treatment and clinical evolution.

It is known that dysphagia is a symptom with a major social and psychological impact, negatively affecting quality of life. ${ }^{13}$ In our sample, despite major symptomatic improvement after surgery, $48 \%$ of patients still reported some level of anxiety and $26 \%$ showed a mild level of depression. Patients with higher anxiety and depression levels also presented lower levels of quality of life, mainly because they scored lower in the four health concepts of the mental health of SF-36: emotional problems, social functioning, general mental health and vitality; when compared to those who do not present anxiety or depressive symptoms, We assume that this maybe due to the persistence of a minor degree of dysphagia, despite the vast improvement of this symptom after surgery. Olle Ekeberg et al described that the occurrence of a low-grade dysphagia can be psychologically disturbing, and that if this condition is treated, it will improve the quality of life of these patients. ${ }^{13}$

The results obtained from the questionnaire AchalasiaDSQoL, support the ones gathered with the SF-36 Health
Survey, and discriminate that even though most patients are currently satisfied with their health and present no limitations on the quality of meals, there is still a considerable percentage showing mild $(12 \%)$ or moderate to severe limitations (4\%). Likewise, the majority $(71 \%)$ say that it affects their quality of life.

Higher scores in both mental and physical health components of the SF-36 are closely related to higher satisfaction levels with the surgical outcome reported in the present study. Ninety percent of patients are satisfied with the surgery, and a large majority assumed they would choose this treatment option again. This satisfaction level may be related to the long-term symptomatic improvement after surgery, clinically assessed and reported by the patients. The low degree of morbidity associated with the laparoscopic approach of Heller myotomy may as well be regarded identically as a factor influencing patients' satisfaction.

As a result, we can assume that the improvement of symptoms is the sole cause for the improvement of the quality of life reported by patients after surgical treatment. V. Garrides el al corroborates this ideia, by concluding that QoL improves in patients with symptomatic achalasia after therapy, and they assign the degree of improvement on QoL on the degree of improvement of esophageal symptoms. ${ }^{22}$ However, no assessment of the psychological status was performed on that study. 


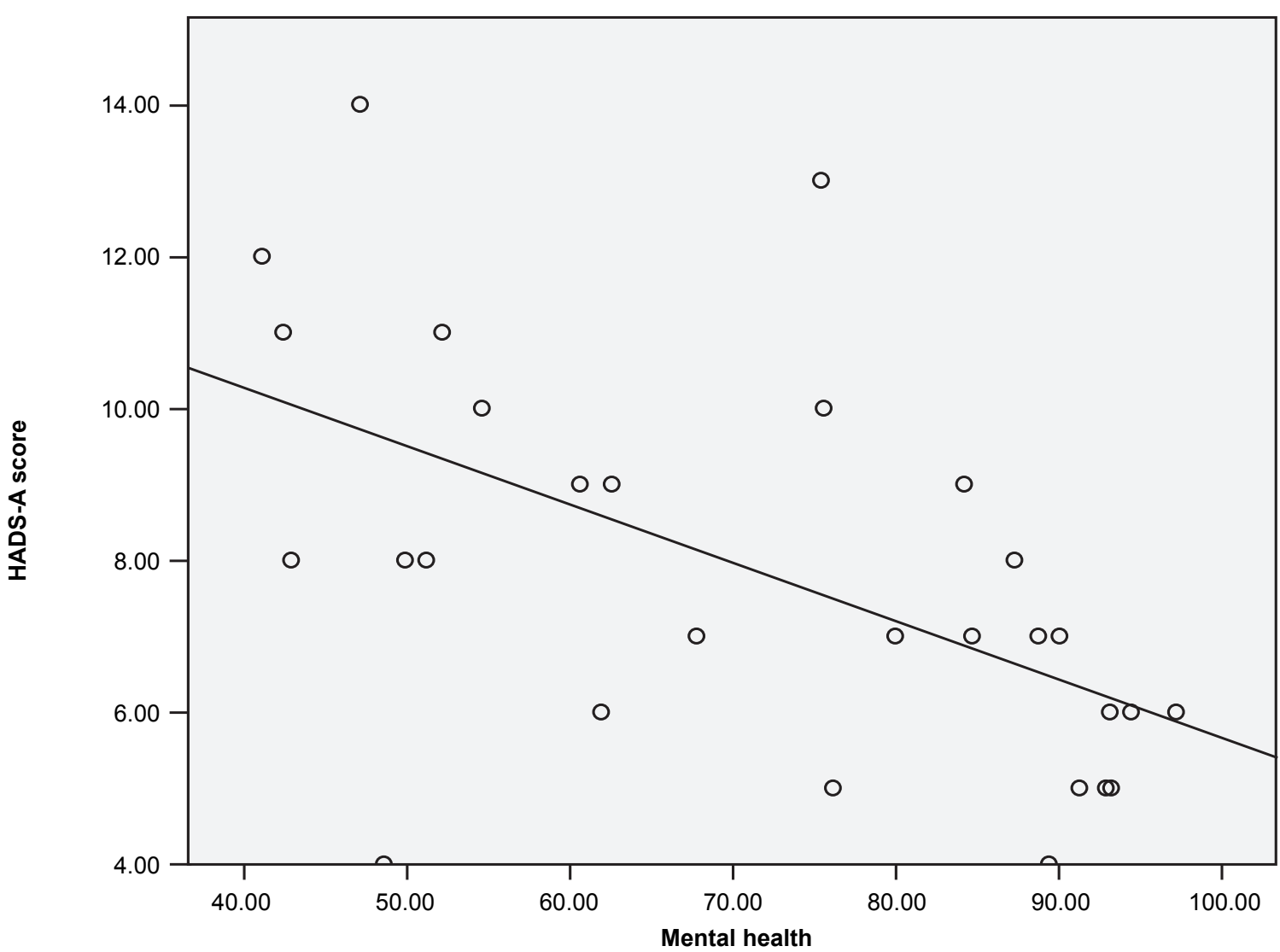

Figure 2 - Simple box plot correlating HADS-A (anxiety) score and the Mental Health domain of SF-36 Health Survey (Pearson correlation coefficient of -0.557 )

So, the remaining issue is at what extent the symptomatic improvement changes the emotional and psychological status of patients. lurenev $\mathrm{GL}$ et al indicated that the use of psychotherapeutic methods, in addition to standard therapy, improves both the physical and psychological states in patients with GERD and this may contribute to a prompter recovery of patients and create preconditions for improving their QoL. Another study on tongue cancer patients by Zhang $L$ et al determines that postoperative dysphagia, depression and anxiety were improved after swallowing training. ${ }^{23}$

Still, even after our study, additional studies are required in order to assess the need for further procedures to treat any residual dysphagia, which can directly affect their quality of life, mainly the psychological state. This finding supports the need for psychotherapy in these patients, since the impact in quality of life will probably be reduced if patients learn how to deal with their disease.

A limitation of the present study is the absence of presurgical evaluation, but given the low prevalence of the disease in our population, a retrospective analysis was chosen instead of a prospective cohort of patients, limiting our pre and post-surgical comparisons. Even with a broad recruitment period, the sample size is small, thus limiting the number of group analyses that can be performed.

\section{CONCLUSION}

Our study corroborates the idea that Heller myotomy with fundoplication is a safe, reliable and effective treatment in the surgical approach of achalasia. It ensured the patients a good quality of life and a very clear improvement in symptoms in the long term, without the need for repeated interventions. In spite of the limitations, we were able to conclude that patients previously diagnosed with achalasia and submitted to Heller myotomy are satisfied with the procedure. In addition, we can also conclude that despite the high levels of satisfaction, some anxiety and depression symptoms remained, pointing for the need of further clarification.

We also think that psychosocial interventions could be useful in specific groups of patients.

\section{ACKNOWLEDGMENTS}

The authors would like to thank J. Costa Maia, head of the Department of General Surgery, for his support in this work.

\section{OBSERVATIONS}

Preliminary results were presented at the IJUP 14 $7^{\text {th }}$ Meeting of Young Research, University of Porto - 12 February 2014, Porto, Portugal. 


\section{CONFLICT OF INTERESTS}

None stated.

\section{FUNDING SOURCES}

Financial support for data collection (mailing): Merck Sharp \& Dohme Portugal.

\section{PROTECTION OF HUMANS AND ANIMALS}

The authors declare that the study was approved by the Ethical Committee "Comissão de Ética para a Saúde do Centro Hospitalar São João" and in accordance to the Helsinki Declaration of the World Medical Association.

\section{DATA CONFIDENTIALITY}

The authors declare having followed the protocols in use at their working center regarding patient's data publication.

treatment. Dysphagia. 2002;17:139-46.

14. Ben-Meir A, Urbach DR, Khajanchee YS, Hansen PD, Swanstrom LL. Quality of life before and after laparoscopic Heller myotomy for achalasia. Am J Surg. 2001;181:471-4

15. Tabola R, Grabowski K, Lewandowski A, Augoff K, Markocka-Maczka K. Achalasia - balloon dilation or surgery? Med Sci Monit. 2013;19:108994.

16. Urbach DR, Tomlinson GA, Harnish JL, Martino R, Diamant NE. A measure of disease-specific health-related quality of life for achalasia. Am J Gastroenterol. 2005;100:1668-76.

17. Frankhuisen $R$, Heijkoop R, van Herwaarden MA, de Vries DR, Smout AJ, Baron A, et al. Validation of a disease-specific quality-of-life questionnaire in a large sample of Dutch achalasia patients. Diseases of the esophagus : official journal of the International Society for Diseases of the Esophagus / ISDE. 2008;21:544-50.

18. Ware JE, Snow KK, Kosinski M, Gandek B, Institute NEMCHH. SF-36 health survey: manual and interpretation guide. Washington: The Health Institute, New England Medical Center; 1993.

19. Ferreira PL. Criação da versão portuguesa do MOS SF-36. Parte I-Adaptação cultural e linguistic. Acta Med Port. 2000;13:55-66.

20. Ware JE Jr., Sherbourne CD. The MOS 36-item short-form health survey (SF-36). I. Conceptual framework and item selection. Med Care. 1992;30:473-83.

21. Zigmond AS, Snaith RP. The hospital anxiety and depression scale. Acta Psychiatr Scand. 1983;67:361-70.

22. Garrigues V, Ortiz V, Casanova C, Bujanda L, Moreno-Osset E, Rodriguez-Tellez $\mathrm{M}$, et al. Disease-specific health-related quality of life in patients with esophageal achalasia before and after therapy. Neurogastroenterol Motil. 2010;22:739-45.

23. Zhang L, Huang Z, Wu H, Chen W, Huang Z. Effect of swallowing training on dysphagia and depression in postoperative tongue cancer patients. Eur J Oncol Nurs. 2014;18:626-9. 